\title{
Where the US stimulus money is going
}

T

he American Recovery and Reinvestment Act, passed by Congress in February 2009, provides about US $\$ 787$ billion of stimulus funding to boost the country's economy.
Here, Nature looks at where $\$ 52.65$ billion of the money for science is being directed. For some concerns about how it is being spent, see page 876 .

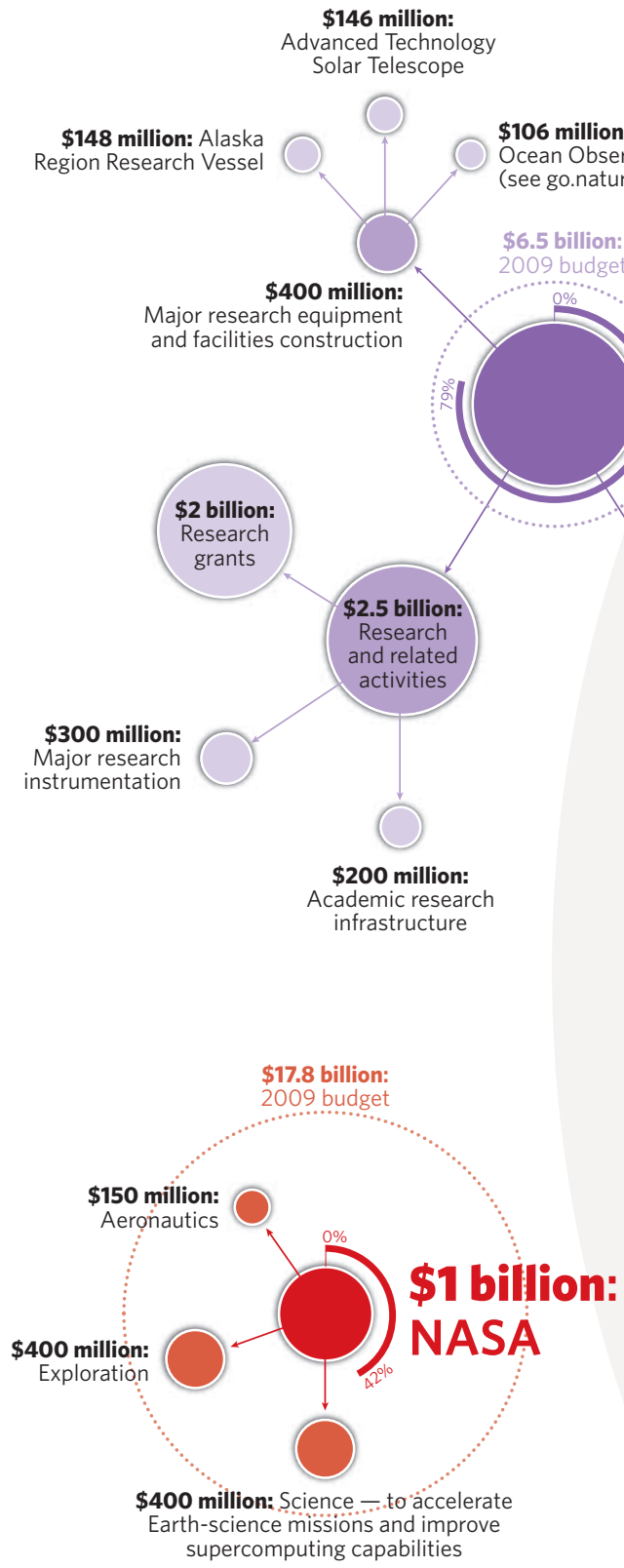
Office of the Director including many new Challenge Grants and Grand Opportunity grants

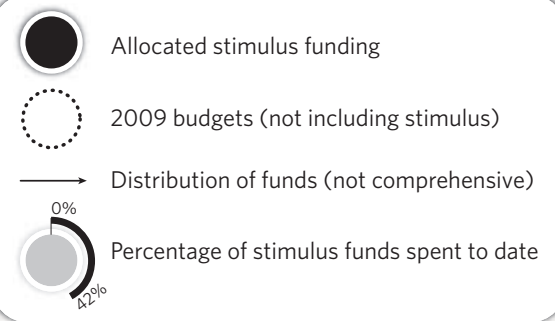

$\$ 7.4$ billion Institutes and centres, in amounts proportional to regular budgetary allocation supercomputing capabilities
$\$ 3$ billion: National Science Foundation

$\$ 100$ million:

Education and human resources

Comparative effectiveness research

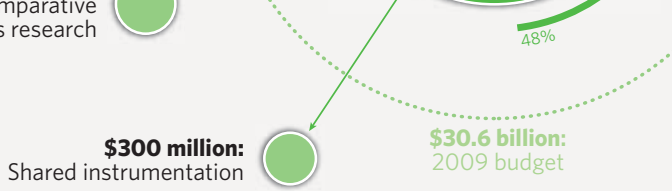

\$10.4 billion: $\mathbf{5 0 0}$ million:
Facilities

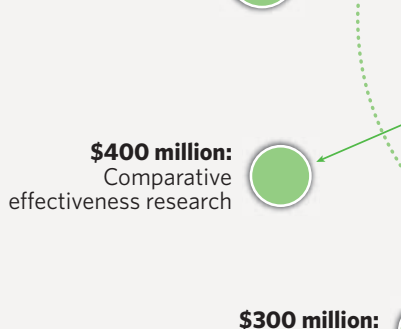
Shared instrumentation

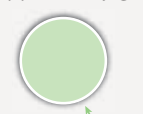
Grants National Institutes of Health

\section{$\$ 580$ million:} National Institute of Standards and Technology (core funding) 


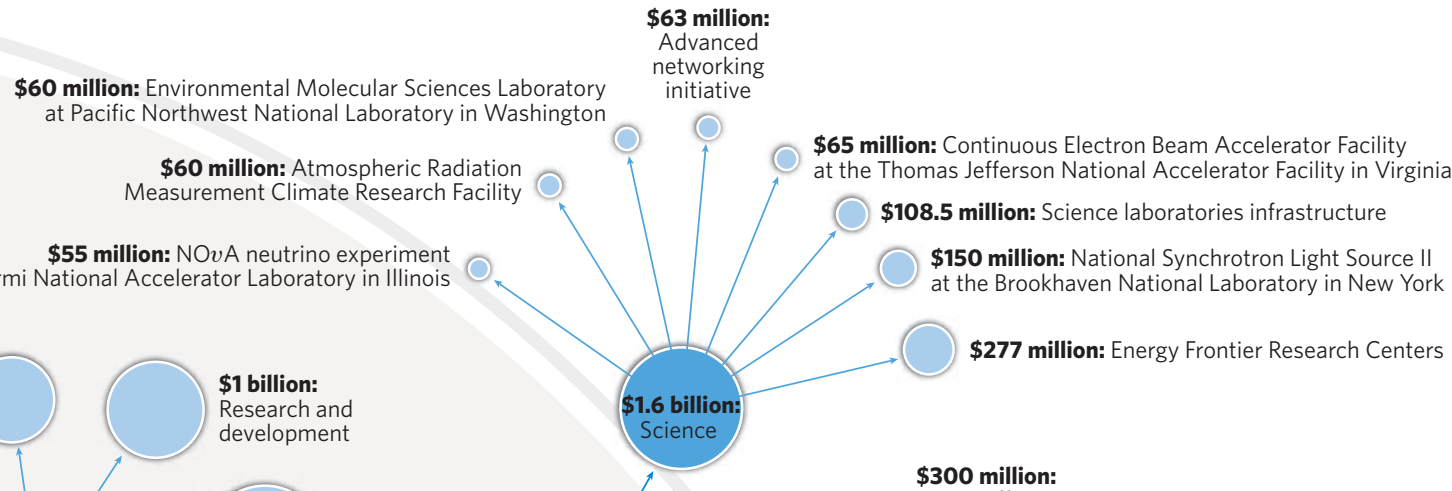

\section{$\$ 70$ million:}

$\mathrm{CO}_{2}$ sequestration

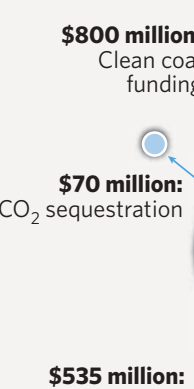

$\$ 535$ million: Solar-panel maker Solyndra of Fremont, California

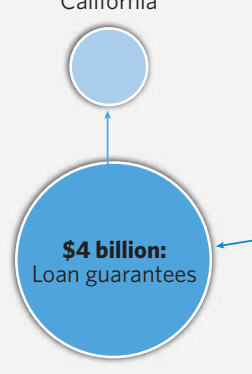

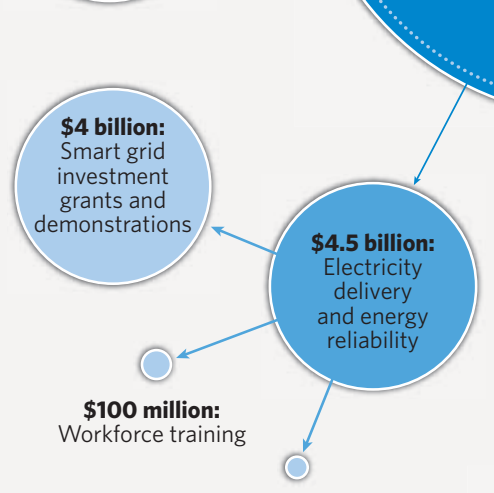

$\$ 60$ million: Resource assessment and interconnectionlevel transmission

$\$ 36.7$ billion: Department of Energy 